\title{
Correction to: Thomson effect and nonlinear performance of thermoelectric generator
}

\author{
Chika Maduabuchi ${ }^{1,2}$ (1) $\cdot$ Ravita Lamba ${ }^{3} \cdot$ Chigbogu Ozoegwu $^{4,5,1} \cdot$ Howard O. Njoku ${ }^{5,6} \cdot$ Mkpamdi Eke $^{4}$. \\ Yuri G. Gurevich ${ }^{7}$ Emenike C. Ejiogu ${ }^{1,2,8}$
}

Published online: 25 November 2021

(c) Springer-Verlag GmbH Germany, part of Springer Nature 2021

\section{Correction to: Heat and Mass Transfer https://doi.org/10.1007/s00231-021-03153-3}

The additional affiliation for Prof Emenike C. Ejiogu is as follows:

Department of Electrical and Electronic Engineering Science, University of Johannesburg, South Africa.

Publisher's Note Springer Nature remains neutral with regard to jurisdictional claims in published maps and institutional affiliations.

The original article can be found online at https://doi.org/10.1007/ s00231-021-03153-3.

Chika Maduabuchi

Chika.maduabuchi.191341@unn.edu.ng

$\triangle$ Mkpamdi Eke

mkpamdi.eke@unn.edu.ng

1 Africa Centre of Excellence for Sustainable Power and Energy Development, University of Nigeria, Nsukka, Nigeria

2 Laboratory of Industrial Electronics, Power Devices and New Energy Systems (LIEPNES), University of Nigeria, Nsukka, Nigeria

3 Department of Electrical Engineering, Malaviya National Institute of Technology, Jaipur 302017, India

4 Department of Mechanical Engineering, University of Nigeria, 410001, NsukkaEnugu, Nigeria
5 Department of Mechanical Engineering Science, University of Johannesburg, Auckland Park 2006, South Africa

6 Applied Renewable and Sustainable Energy Research Group, Department of Mechanical Engineering, University of Nigeria, Nsukka 410001, Nigeria

7 Departamento de Física, Centro de Investigación Y de Estudios Avanzados del IPN, CDMX, Av. IPN 2508, 07360 México, México

8 Department of Electrical and Electronic Engineering Science, University of Johannesburg, Johannesburg, South Africa 